\title{
Shaping the future for quality: initiating active surveillance as foundation to drive improvement for health care-associated infections
}

\author{
Ng Wai Khuan, Helge Springhorn \\ Quality \& Risk Management Department, Mafraq Hospital, \\ Abu Dhabi, United Arab Emirates
}

\begin{abstract}
Prior to April 2008, there was only total house surveillance. In total (or whole house) surveillance, all types of health care-associated infections (HCAls) are monitored in the entire organization of Mafraq Hospital. Overall infection rates were not adjusted for specific infection or injury risks. The trends were not measured over time; no comparisons were made between groups, either interhospital or intrahospital, nor was benchmarking done. A thorough facility-wide infection prevention and control risk assessment was performed in March 2008 by the only certified, newly employed infection preventionist.

After completion of the risk assessment, the data and information was collated and presented. The infection preventionist proposed the urgent implementation of an active targeted and modified total house surveillance program to monitor all patients admitted to Mafraq Intensive Care Units (ICUs). Total house surveillance was also modified to target only populations in intensive care units. A surveillance plan was developed with emphasis on the following: central line-associated bloodstream infection (CLABSI), ventilator-associated pneumonia (VAP), catheter-associated urinary tract infection (CAUTI) and healthcare-associated multidrugresistant organism (HA-MDRO). The active targeted and modified total house surveillance program was initiated only within Mafraq intensive care units in April 2008. Since then, hand hygiene compliance monitoring and educational program were gradually implemented.
\end{abstract}

\section{Corresponding Author}

$\mathrm{Ng}$ Wai Khuan

Quality Department, Mafraq Hospital, P.O. Box 2951, Abu Dhabi, United Arab Emirates

Email details: nkhuan@mafraqhospital.ae

Tel: 00971505825689 
As active surveillance improved within Mafraq ICUs, it was noted that, during this period, healthcare-associated infection rates (i.e., CLABSI, VAP, CAUTI, and HA-MDRO in Mafraq ICUs decreased from 2nd quarter 2008 till 2nd quarter 2012.

The limitations of this study include absence of comparable data before active surveillance initiated in April 2008, lack of information on population variability. The evidence from the active targeted and modified total house surveillance in Mafraq ICUs showed a decrease in healthcare-associated infections since the initiation in 2nd quarter 2008 till 2nd quarter 2012. Therefore, it can be concluded that HCAls can be significantly impacted through the implementation of an active surveillance program.

\section{Key words}

Infection control; Cross infection, prevention and control; Quality of health care+utilization

\section{Introduction}

The global healthcare system is not as safe as it should be; but can be managed, once it is measured. Health care associated infections (HCAls) account for preventable morbidity and mortality among hospitalized patients worldwide. ${ }^{1,2}$ Surveillance is conducted by infection preventionists to provide data and it plays a critical role in determining endemic HCAI rates, early epidemic detection, implementing risk-reduction strategies and assessment of the efficacy of interventions. ${ }^{3}$

Surveillance is defined as the "ongoing data collection, collation, and analysis and the ongoing dissemination of information to those who need to know, so that prompt action can be implemented to reduce morbidity and mortality and to improve health" ${ }^{1,4,5}$ Surveillance of HCAls is also an essential component of an effective infection prevention and control program. ${ }^{1,6,7}$

We observed a reduction of HCAls during a 4 year period after initiation of an active targeted and modified total house surveillance program within Mafraq intensive care units in April 2008.

\section{Background}

Mafraq Hospital is a 450 bed tertiary care hospital. Prior to April 2008, there was only total house surveillance to monitor all types of HCAls in the entire organization. The overall infection rates were not adjusted for specific infection or injury risks. The trends were not measured over time; no comparisons were made between groups, either interhospital or intrahospital, nor was benchmarking done.
A thorough facility-wide infection prevention and control risk assessment was performed by the only certified infection preventionist over a period of 2 weeks in March 2008. The types of populations served (i.e., newborn, paediatric, adult, geriatric), services provided (i.e., medical, surgical, ambulatory care), procedures performed and acuity of care were assessed and the risk factors (e.g., conditions and diseases present in the population) for healthcareassociated infections or other adverse outcome were identified. ${ }^{4}$ Healthcare workers who may be affected by the risks were also consulted during the risk assessment process. This was done after understanding the regulatory and accrediting agency (such as Abu Dhabi Health Services [SEHA], Health Authority of Abu Dhabi [HAAD]) requirements, available resources, availability of required data, performance improvement initiatives and organizational objectives.

\section{Methods}

After completion of the risk assessment, the data and information was collated by the infection preventionist and the Assistant Director of Nursing, Education (now Director of Quality), and presented to the executive team. The infection preventionist proposed the implementation of an active targeted and modified total house surveillance program for device-associated infections (i.e., CLABSI, VAP and CAUTI) and healthcare-associated multidrug-resistant organism (HA-MDRO) in Mafraq intensive care units (ICUs). This program included all patients admitted to Mafraq intensive care units (i.e., Medical-Surgical Intensive Care Unit [MSICU], Cardiac Intensive Care Unit [CICU] and Burns Unit). 
A surveillance plan was developed, and included outcome and process measures which have the most important relevance to the population served and identified risk factors. ${ }^{8}$ Based on this, it was concluded that hand hygiene compliance monitoring was selected as the process indicator, while the outcome indicators selected to monitor healthcare-associated infections were CLABSI, VAP, CAUTI and HA-MDRO. HA-MDRO is defined as colonization or infection with bacteria that are resistant to 3 or more classes of antimicrobial agents (i.e., beta-lactams [penicillins, monobactams, cephalosporins], fluoroquinolones, aminoglycosides or carbapenems) which were identified 48 hours after admission to Mafraq ICUs. Colonization is defined as the presence of bacteria on a body surface without causing disease in a person. However, MDRO either colonized or infected is transmissible and therefore, patients admitted to Mafraq ICUs were screened for MDRO within 48 hours. This is not only to rule out community-acquired MDRO but also to institute prompt contact precautions, if MDRO is identified to prevent it from transmitting to other patients in ICUs.

The active targeted and modified total house surveillance program was officially initiated in intensive care units in April 2008, since there was only one certified infection preventionist during that time. The infection preventionist visited the intensive care units (ICUs) daily to 'look up' device-associated infections (i.e., CLABSI, VAP, and CAUTI). All laboratory results pertaining to MSICU, CICU and Burns Unit were also monitored to identify both colonized and infected ICU patients with HA-MDRO. The Centers for Disease Control and Prevention (CDC) National Healthcare Safety Network (NHSN) device associated events criteria were used to guide in identifying healthcare-associated infections related to use of central line, ventilator and indwelling urinary catheter. Obtained surveillance data was copied from data collection forms into a computer database to be sorted and analyzed.

Following completion of data analysis, the collated surveillance data was then organized, summarized and visually displayed in tables and graphs in order to provide monthly feedback to key stakeholders and to stimulate performance improvement activities. ${ }^{4}$ Since there was no comparable data from previous years to be used as intrahospital benchmark, the Centers for Disease Control and Prevention (CDC)
National Healthcare Safety Network (NHSN) 2006 ICU benchmark was adopted as the interhospital benchmark to understand the status of healthcareassociated infections in Mafraq ICUs, while the CDC and WHO benchmark, which is $50 \%$, was adopted as the hand hygiene compliance benchmark. However, since there is no standardized CDC benchmark available for HA-MDRO, Mafraq ICU prior year mean was used as intrahospital comparison. Hand hygiene compliance rate and healthcare-associated infection (i.e., CLABSI, VAP, CAUTI and ICU HA-MDRO) data were compared throughout 2nd quarter 2008 to 2012.

In addition to the initiation of active targeted and modified total house surveillance as performance improvement activity, what was also revealed were deficiencies in attitude, knowledge, and skills among healthcare workers in the ICUs. These deficiencies served as the basis to develop an educational program. Thus, the infection preventionist addressed these deficiencies during the daily surveillance round, infection prevention and control committee meetings, infection prevention and control general orientation and unit-based infection prevention and control training. This was to educate and train healthcare workers on evidence-based infection prevention and control facts and guide on appropriate infection prevention and control practices.

\section{Results}

In this study only ICUs hand hygiene compliance rate and healthcare-associated infection (i.e., CLABSI, VAP, CAUTI and ICU HA-MDRO) data are compared throughout 2nd quarter 2008 to 2012.

Firstly, hand hygiene compliance rate in the ICUs increased from 38\% in 2008 to $87 \%$ in mid-2012 as shown in figure 1. It was also noted that, during this period, CLABSI decreased from 18.6/1000 central line days (95\% Cl 7.3-49.2) in April 2008 to 0 (95\% Cl 0.07.3) in April 2012 or from 10.7/1000 central line days $(95 \% \mathrm{Cl} 5.6-20.5)$ in the $2^{\text {nd }}$ quarter of 2008 to 1.5 $(95 \% \mathrm{Cl} 0.4-5.5)$ in the $2^{\text {nd }}$ quarter of 2012 (see Table I and II and Figure 2). VAP decreased from 19.4/1000 ventilator days (95\% Cl 9.0-43.4) in April 2008 to 1.9 (95\% Cl 0.3-10.7) in April 2012, or 12.2/1000 ventilator days $(95 \% \mathrm{Cl} 6.9-22.2)$ in the $2^{\text {nd }}$ quarter of 2008 to $0.6(95 \% \mathrm{Cl} 0.1-3.3)$ in the $2^{\text {nd }}$ quarter of 2012 (see Table I and II and Figure 3). 
Table I: Mafraq Hospital Intensive Care Units Healthcare-Associated Infections April 2008, 2009, 2010, 2011 \& 2012

\begin{tabular}{|c|c|c|c|c|c|}
\hline & 2008 & 2009 & 2010 & 2011 & 2012 \\
\hline Central Line Day & 215 & 291 & 286 & 434 & 525 \\
\hline CLABSI Incidence Rate/1000 & 18.6 & 13.7 & 7 & $\mathbf{0}$ & $\mathbf{0}$ \\
\hline \multicolumn{6}{|l|}{ Central Line Days } \\
\hline 95\% Confidence Interval (CI) & $7.3-49.2$ & $5.4-36.1$ & $1.9-25.8$ & $0.0-8.9$ & $0.0-7.3$ \\
\hline Odds Ratio & 19.0 & 13.9 & 7.0 & 0 & 0 \\
\hline Ventilator Day & 310 & 355 & 250 & 451 & 531 \\
\hline VAP Incidence Rate/1000 & 19.4 & 14.1 & 8 & 2.2 & 1.9 \\
\hline \multicolumn{6}{|l|}{ Ventilator Days } \\
\hline 95\% Confidence Interval (CI) & $9.0-43.4$ & $6.1-33.6$ & $2.0-29.5$ & $0.4-12.6$ & $0.3-10.7$ \\
\hline Odds Ratio & 19.7 & 14.3 & 8.1 & 2.2 & 1.9 \\
\hline Urinary Catheter Day & 566 & 375 & 670 & 654 & 814 \\
\hline CAUTI Incidence Rate/1000 & 5.3 & 5.3 & 3 & 1.5 & 1.2 \\
\hline \multicolumn{6}{|l|}{ Urinary Catheter Days } \\
\hline 95\% Confidence Interval (CI) & $1.8-15.7$ & $1.5-19.6$ & $0.8-10.9$ & $0.3-8.7$ & $0.2-7.0$ \\
\hline Odds Ratio & 5.3 & 5.4 & 3.0 & 1.5 & 1.2 \\
\hline Patient Day & 566 & 1041 & 1050 & 1176 & 1309 \\
\hline HA-MDRO Incidence Rate/1000 & 26.5 & 18.3 & 12.4 & 8.5 & 7.6 \\
\hline \multicolumn{6}{|l|}{ Patient Days } \\
\hline 95\% Confidence Interval (CI) & $16.4-45.2$ & $11.9-29.2$ & $7.3-21.5$ & $4.6-15.8$ & $4.2-14.2$ \\
\hline Odds Ratio & 27.2 & 18.6 & 12.5 & 8.6 & 7.7 \\
\hline
\end{tabular}

Even CAUTI decreased from 5.3/1000 urinary catheter days $(95 \% \mathrm{Cl} 1.8-15.7)$ in April 2008 to $1.2(95 \% \mathrm{Cl}$ 0.2-7.0) in April 2012, or 3.3/1000 urinary catheter days $(95 \% \mathrm{Cl} 1.5-7.1)$ in the $2^{\text {nd }}$ quarter of 2008 to $1.6(95 \% \mathrm{Cl} 0.6-4.1)$ in the $2^{\text {nd }}$ quarter of 2012 (see Table I and II and Figure 4). HA-MDRO also decreased from $26.5 / 1000$ patient days $(95 \% \mathrm{Cl} 16.4-45.2)$ in April 2008 to 7.6 (95\% Cl 4.2-14.2) in April 2012, or $17.4 / 1000$ patient days $(95 \% \mathrm{Cl} 13.3-23.6)$ in the $2^{\text {nd }}$ quarter of 2008 to $10.6(95 \% \mathrm{Cl} 7.9-14.6)$ in the $2^{\text {nd }}$ quarter of 2012 (see Table I and II and Figure 5).

The results revealed that CLABSI, VAP and CAUTI in the ICUs rates were higher than the CDC 2006 ICU benchmark $^{9}$ (see Figures 2, 3 and 4). Subsequently, the CLABSI, VAP and CAUTI rates decreased in April 2009, 2010, 2011 and 2012. The rates for 2009 and 2010 were still higher than CDC 2007 \& 2008 ICU benchmarks ${ }^{10,11}$ (see figure 2, 3 and 4). Only in 2011 and 2012, the device-associated infection (i.e., CLABSI, VAP and CAUTI) rates decreased below the CDC 2009 \& 2010 ICU benchmarks ${ }^{12,13}$ (see figure 2, 3 and 4). The same decrease was observed when comparing the data from the whole $2^{\text {nd }}$ quarter for the years 2009 to 2012 (see Figure 2, 3 and 4). ICUs HA-MDRO rate was only compared intrahospital (i.e., Mafraq ICU prior year mean) but not externally, since standardized CDC benchmark is not available (see Figure 5). 
Table II. Mafraq hospital intensive care units health care-associated infections $2^{\text {nd }}$ quarter 2008 to 2012

\begin{tabular}{lrrrrr} 
& $\mathbf{2 0 0 8}$ & $\mathbf{2 0 0 9}$ & $\mathbf{2 0 1 0}$ & $\mathbf{2 0 1 1}$ & $\mathbf{2 0 1 2}$ \\
\hline Central Line Day & 845 & 865 & 873 & 1476 & 1334 \\
CLABSI Incidence Rate/1000 Central & 10.7 & 9.2 & 6.9 & 2 & 1.5
\end{tabular}

Line Days

\begin{tabular}{|c|c|c|c|c|c|}
\hline 95\% Confidence Interval $(\mathrm{CI})$ & $5.6-20.5$ & $4.7-18.5$ & $3.2-15.1$ & $0.7-6.0$ & $0.4-5.5$ \\
\hline Odds Ratio & 10.8 & 9.3 & 6.9 & 2.0 & 1.5 \\
\hline Ventilator Day & 903 & 988 & 882 & 1378 & 1703 \\
\hline $\begin{array}{l}\text { VAP Incidence Rate/1000 Ventilator } \\
\text { Days }\end{array}$ & 12.2 & 12.1 & 6.8 & 2.2 & 0.6 \\
\hline 95\% Confidence Interval (CI) & $6.9-22.2$ & $7.0-21.6$ & $3.1-15.0$ & $0.7-6.4$ & $0.1-3.3$ \\
\hline Odds Ratio & 12.3 & 12.3 & 6.8 & 2.2 & 0.6 \\
\hline Urinary Catheter Day & 1848 & 1655 & 1769 & 1831 & 2509 \\
\hline $\begin{array}{l}\text { CAUTI Incidence Rate/1000 Urinary } \\
\text { Catheter Days }\end{array}$ & 3.3 & 2.4 & 1.7 & 1.6 & 1.6 \\
\hline 95\% Confidence Interval $(\mathrm{Cl})$ & $1.5-7.1$ & $0.9-6.2$ & $0.6-5.0$ & $0.6-4.8$ & $0.6-4.1$ \\
\hline Odds Ratio & 3.3 & 2.4 & 1.7 & 1.6 & 1.6 \\
\hline Patient Day & 2700 & 3015 & 3365 & 3316 & 3946 \\
\hline $\begin{array}{l}\text { HA-MDRO Incidence } \\
\text { Patient Days }\end{array}$ & 17.4 & 13.9 & 11.3 & 10.9 & 10.6 \\
\hline 95\% Confidence Interval $(\mathrm{Cl})$ & $13.3-23.6$ & $10.4-19.1$ & $8.3-15.7$ & $7.9-15.2$ & $7.9-14.6$ \\
\hline Odds Ratio & 17.7 & 14.1 & 11.4 & 11.0 & 10.8 \\
\hline
\end{tabular}

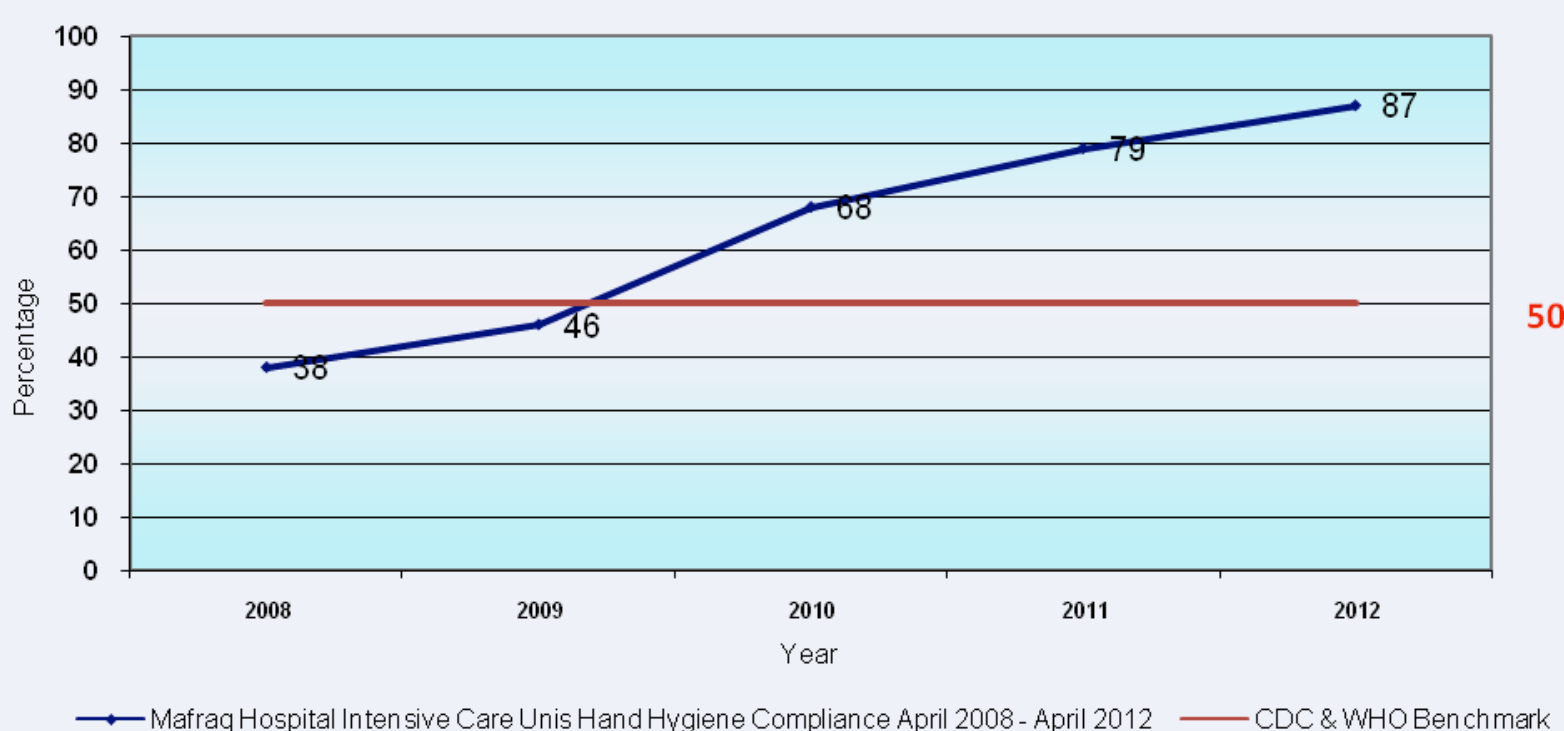

Figure 1. Mafraq hospital intensive care units hand hygiene compliance rates April 2008 till April 2012 


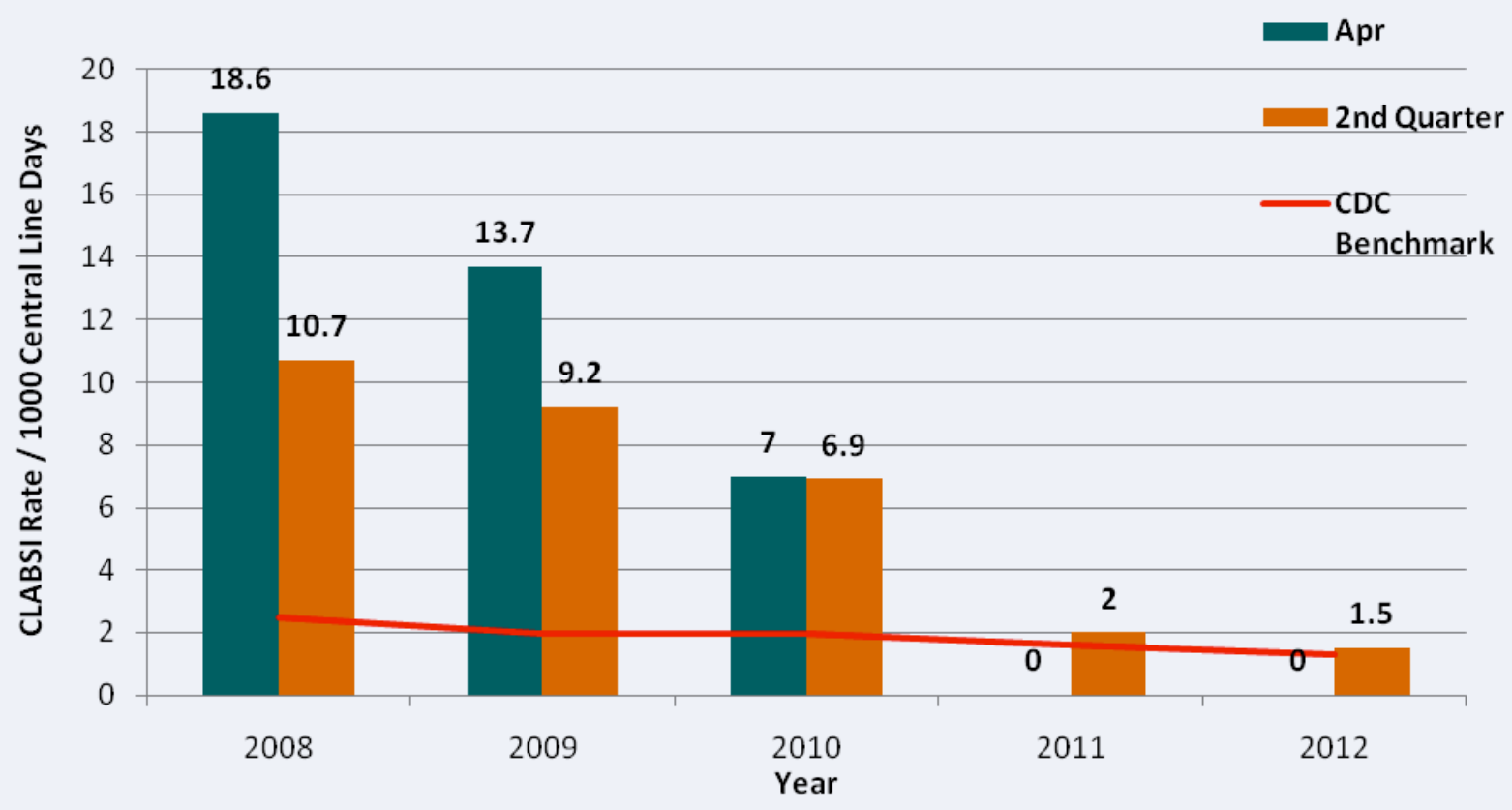

Figure 2. Mafraq hospital intensive care units central-line associated bloodstream infection (CLABSI) rates April 2008 till April 2012

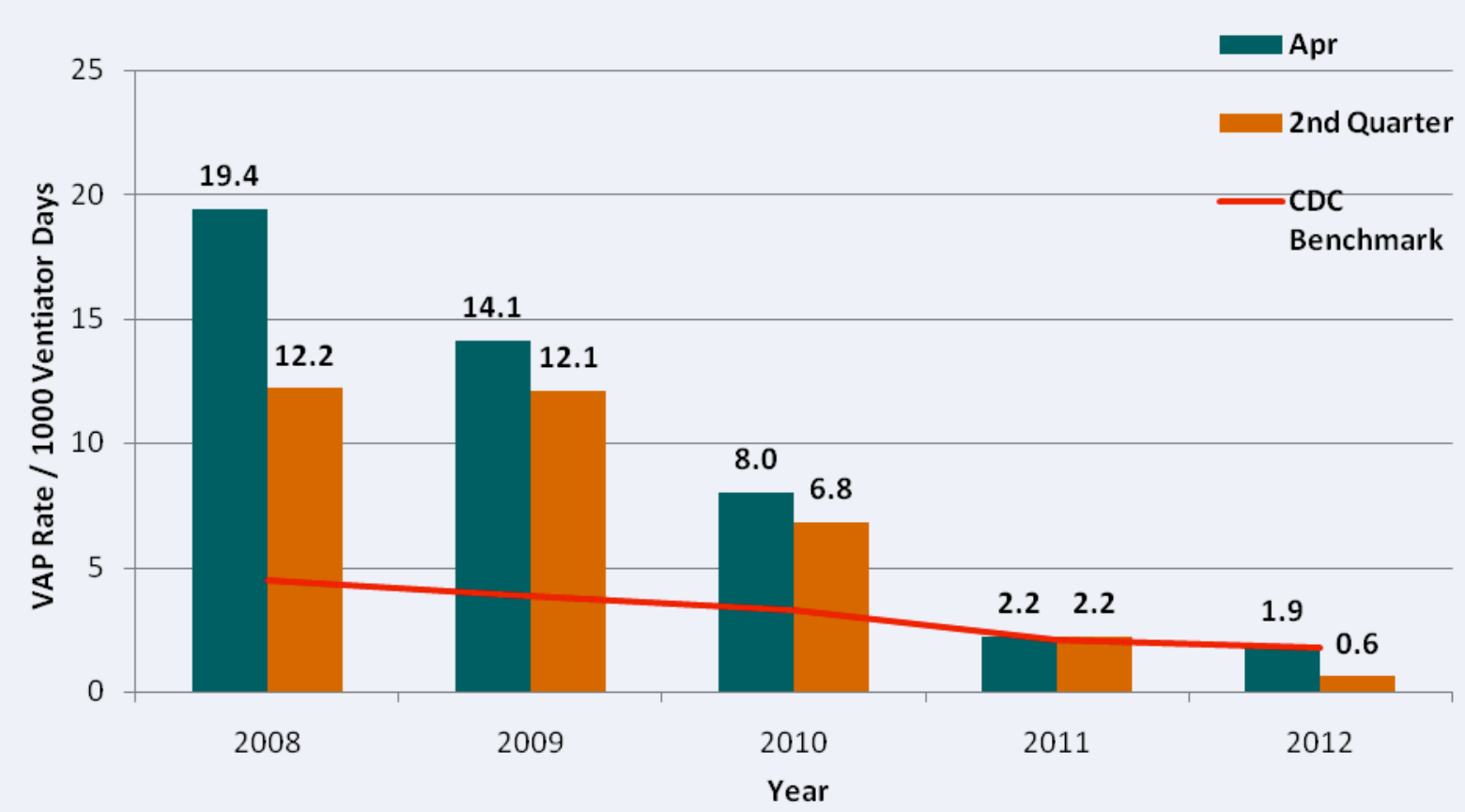

Figure 3. Mafraq hospital intensive care units ventilator-associated pneumonia (VAP) rates April 2008 till April 2012 


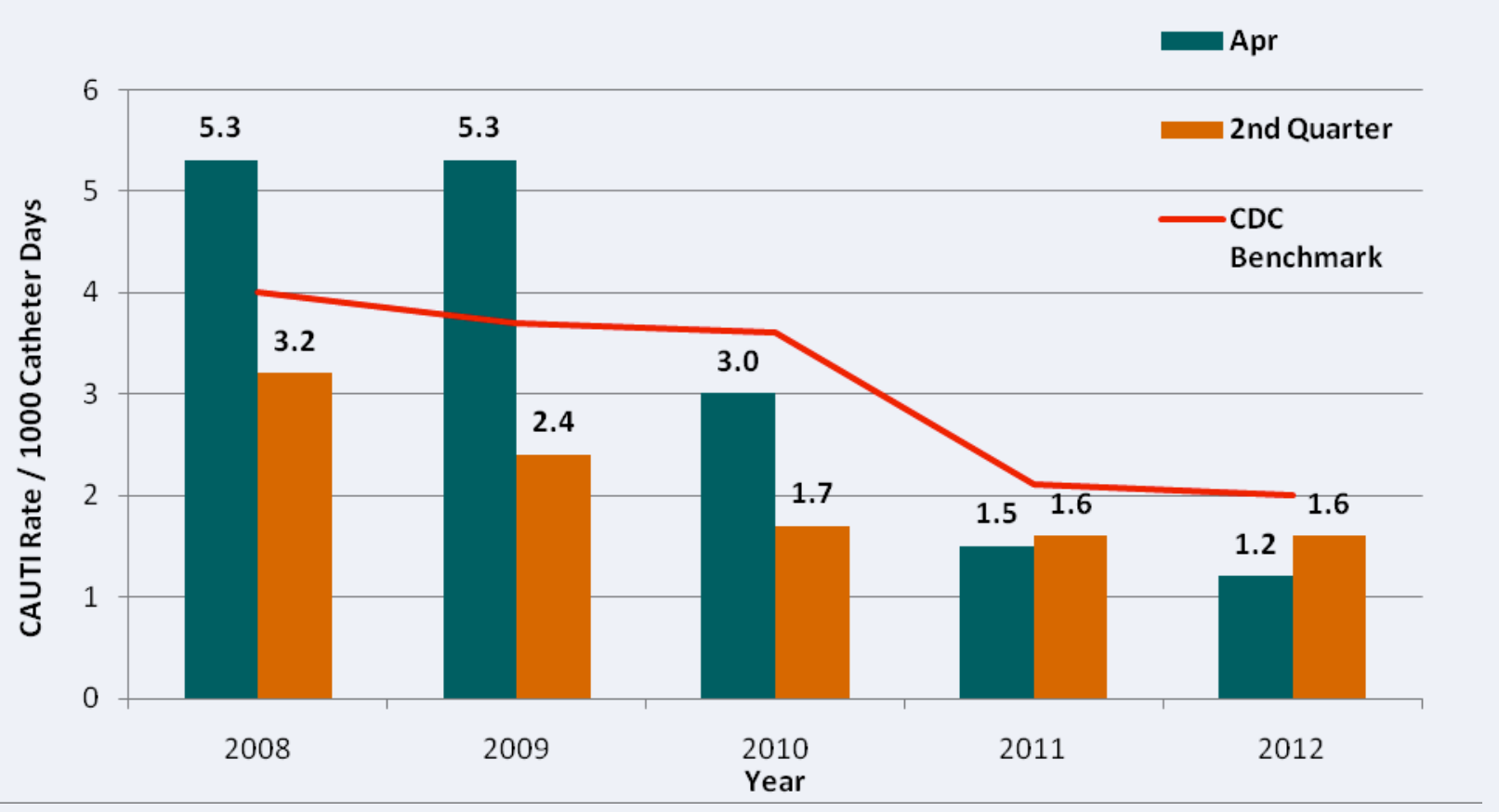

Figure 4. Mafraq hospital intensive care units catheter-associated urinary tract infection (CAUTI) rates April 2008 till April 2012

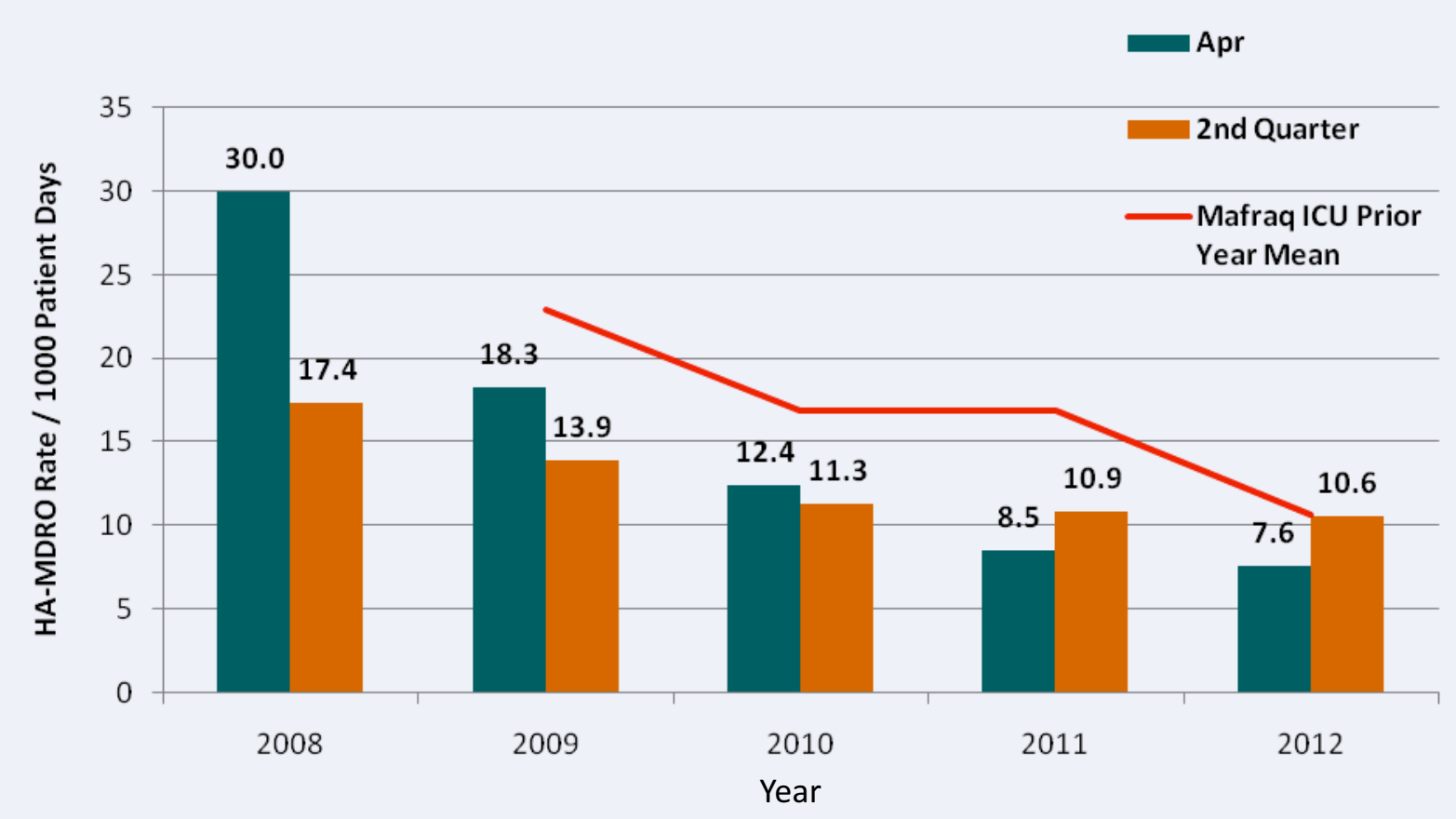

Figure 5. Mafraq hospital intensive care units health care-associated multidrug-resistant organism (HA-MDRO) rates April 2008 till April 2012 


\section{Discussion}

Targeted and modified total house surveillance is a combined surveillance strategy which monitors high risk, high volume, highly preventable and targeted events occurring in a defined population (e.g., intensive care units). ${ }^{4,14,15,16}$ Total house surveillance was also modified to target only populations in intensive care units, since total house surveillance has been discouraged by most-experts due to crude overall rates not being sensitive enough to identify potential problems and thus cannot be used to target performance improvement activities. . $1,17-19^{-19}$

Moreover, surveillance can be active with a process for identifying cases of interest, or passive which depends on the healthcare workers (e.g., nurses) to complete a form or chart and notify. In the field of healthcareassociated infections, passive surveillance has almost always been reported as underestimating cases. ${ }^{14,20}$ However, active surveillance requires substantially more time as it is labour-intensive and is therefore not adopted by most healthcare settings. With a focus on decreasing healthcare-costs, today's healthcare systems have increased attention to interventions that accurately measure and report data. Wise institutions will value the existence of an epidemiologically sound active surveillance program managed by competent and qualified infection preventionists, since such a program can be cost-effective by reducing healthcareassociated infections. ${ }^{21,22}$

In order for the active surveillance and educational program to be effective, to expand and be sustainable, an infection prevention and control team had to be formed. As it is often the case with most of the change initiatives, the first and most important thing to do in preparation for the breakthrough was building a team, getting "the right people on the bus and the right people in the right seats". ${ }^{23}$ In October 2008, 1 nurse was trained as infection preventionist. Since then, there was 1 certified infection preventionist and 1 trainee running the active targeted and modified total house surveillance program in Mafraq ICUs. In January 2010, 3 additional nurses were recruited and trained as infection preventionists. Active processes (i.e., hand hygiene compliance monitoring) and HA-MDRO (i.e., colonized and infected) active surveillance were officially expanded hospital wide in March 2010.
Post-discharge surveillance on surgical site infection for ICUs and hospital wide was also initiated at this time since there was additional manpower. Other process measures including contact precautions compliance monitoring and environmental auditing were also initiated in ICUs and hospital wide, since non-compliance with contact precautions and inappropriate environmental disinfection can possibly lead to the transmission of MDRO from one patient to another, or environment to a patient or vice-versa.

In October 2011, an additional nurse was recruited as infection preventionist, to fulfill the Association for Professionals in Infection Control and Epidemiology (APIC) recommendation to have a ratio of 0.8 to 1.0 infection preventionist for every 100 occupied acute care beds; this recommendation was based on the study results from a Delphi project initiated by APIC. ${ }^{24}$ Mafraq ICUs have shown a decrease in HCAI (i.e., CLABSI, VAP, CAUTI and HA-MDRO) rates over a period of 48 months. It can be concluded that HCAls can be impacted through the implementation of an active surveillance program and addition of educational program and infection preventionists. Although external benchmarking can be misleading since all facilities are different, data can be meaningful when the standardized definitions and the same populations are used for effective risk stratification. The hand hygiene compliance rates in 2008 and 2009 were lower than the CDC and WHO benchmark, but increased starting in 2010 since the implementation of multimodal approach (i.e., hand hygiene campaigns).

Since it is understood that a process surveillance program is directly related with outcome objectives, ${ }^{25}$ process surveillance was carried out actively by infection preventionists throughout Mafraq ICUs. Combining process and outcome results can enable an organization to effectively target prevention and control strategies. ${ }^{11}$ Furthermore, central line and ventilator bundles ${ }^{26}{ }^{27}$ were also initiated in intensive care units (i.e., MSICU, CICU and Burns Unit) in May 2010 paralleled with an ongoing process surveillance to monitor and promote bundles compliance. Moreover, the HCAI rates were communicated to all relevant key-stakeholders periodically (i.e., monthly). This might have impacted the decrease. As active surveillance, education and feedback improved, it 
was noted that, during the same time, the HCAI rates decreased.

However, the limitations of this study are as follows: 1) there was no active surveillance before April 2008 and it was not possible to compare; 2) the lack of information on population variability, thus it could be argued that this could have affected the decrease in HCAls; 3) the lack of information on antimicrobial selection and utilization monitoring, thus the decrease in HA-MDRO could be due to accurate and prompt diagnosis and treatment, and judicious antimicrobial selection and utilization; 4) it is not sure whether the decrease in device-associated infections (i.e., CLABSI, VAP and UTI) could possibly reduce antimicrobial use and decrease opportunities for emergence and transmission of MDROs.

A structured and well-implemented surveillance plan will serve a crucial role in supporting high-quality care initiatives by providing systems for monitoring, measuring, and reporting important outcomes and processes. ${ }^{8}$ Surveillance is not only to better describe HCAls, risk factors, and affected populations, but to use the data in promoting and improving the quality of patient care. Effective active surveillance and quality improvement programs are those that use data for evaluating and improving clinical processes and outcomes. ${ }^{28}$ For the active surveillance program to continue to be effective, it will have to be evaluated periodically (e.g., yearly) to assess its usefulness and ability to fulfill the objectives of an organization. ${ }^{4}$

A hospital's primary aim to the patient, as it has been for centuries, is to do no harm. The focus is on protecting the patient from the risks of acquiring healthcare-associated infections. Although active surveillance is a vital element of an effective infection prevention and control program, it consumes too much time of an infection preventionist and this limits the time available for education, training and performance improvement activities. ${ }^{6}$ Thus, infection preventionists in most organizations often allow automated electronic technology to alter the manner in which passive surveillance is performed, since it may ease the burden of data management and allow them to "go forth and accomplish the profession's highest calling: prevention." ${ }^{\prime 29}$
In fact, active surveillance is always more superior than passive surveillance, no matter how sophisticated the computer program or how many gigabytes of memory available. Effective active surveillance does not necessarily ensure that the right decisions are made, but it reduces the risks of wrong ones. ${ }^{30}$ Therefore, infection preventionists need to enhance the surveillance skills and insist on using epidemiologically sound active surveillance methods in their infection surveillance and control programs. Only when this is done, will we be able to auspiciously prevent healthcare-associated infections and shape the future for quality.

\section{Acknowledgements}

The authors would like to acknowledge the great efforts and hard work of the infection prevention and control team - Ms. Reham Jafer, Ms. Prameela Maniamma, Ms. Fathia Jama Osman and Ms. Jancy Varghese who are participating in the active surveillance program. Secondly, the authors would also like to thank Ms. Gail Smith (ex-Chief Nursing Officer, Mafraq Hospital) for her full support to the initiation of active targeted and modified total house surveillance program. The authors would also like to thank the executive team for their support to the infection prevention and control program.

\section{References}

1. Weber DJ, Sickbert-Benett EE, Brown V, Rutala W. Comparison of Hospital Wide Surveillance and Targeted Intensive Care Unit Surveillance of Healthcare-Associated Infections. American Journal of Infection Control 2007; 28(12): 13611366.

2. Jarvis WR. Selected aspects of the socioeconomic impact of nosocomial infections: Morbidity, mortality, cost, and prevention. Infect Control Hosp Epidemiology 1996 Aug; 17(8): 552-557. http://dx.doi.org/10.1086/647371

3. Schekler WE, Brimhall D, Buck AS, et al. Requirements for Infrastructure and Essential Activities of Infection Control and Epidemiology in Hospitals: A Consensus Panel Report. Infection Control and Hospital Epidemiology 1998; 19(2): 114-124. http://dx.doi.org/10.1086/647779

4. Arias KM. Surveillance. In: Association for Professionals in Infection Control and Epidemiology, Eds. APIC Text of Infection Control and Epidemiology, 3rd edn. Washington, DC: Association for Professionals in Infection Control and Epidemiology 2009; 1-17.

5. Centers for Disease Control and Prevention. Updated guidelines for evaluating public health surveillance systems: recommendations from the guidelines working group. Morbidity \& Mortality Week Report 2001; 50: 1-35.

6. Greene LR, Cain TA., Khoury R, Krystofiak SP, Patrick M, Streed S. APIC position paper: The importance of surveillance technologies in the prevention of healthcare-associated infections. American Journal of Infection Control 2009; 37(6): 510-513. http://dx.doi.org/10.1016/j.ajic.2009.06.001 
7. Gamage B, Varia M, Litt M, Pugh S, Bryce E. Finding the gaps: An assessment of infection control surveillance needs in British Columbia acute care facilities. American Journal of Infection Control 2008; 36(10): 706-710. http://dx.doi. org/10.1016/j.ajic.2008.06.004

8. Lee TB, Montgomery OG, Marx J, Olmsted RN, Scheckler WE. Recommended practices for surveillance: Association for Professionals in Infection Control and Epidemiology (APIC) 2007.

9. Edwards JR, Peterson KD, Andrus ML, et al. National Healthcare Safety Network (NHSN) Report, data summary for 2006, issued June 2007. American Journal of Infection Control 2007; 35(5): 290-301. http://dx.doi.org/10.1016/j. ajic.2007.04.001

10. Edwards JR, Peterson KD, Andrus ML, Dudeck MA, Pollock DA, Horan TC. National Healthcare Safety Network (NHSN) Report, data summary for 2006 through 2007, issued November 2008. American Journal of Infection Control 2008; 36(9): 609-626. http://dx.doi.org/10.1016/j.ajic.2008.08.001

11. Edwards JR, Peterson KD, Mu Y, et al. National Healthcare Safety Network (NHSN) report: Data summary for 2006 through 2008, issued December 2009. American Journal of Infection Control 2009; 37(10): 783-805. http://dx.doi. org/10.1016/j.ajic.2009.10.001

12. Centers for Disease Control and Prevention, 2010. National Healthcare Safety Network (NHSN) Annual Reports: 2009 Data. Centers for Disease Control and Prevention, Atlanta, Georgia. http://www.cdc.gov/nhsn/PDFs/ dataStat/2010NHSNReport.pdf [Accessed May 21, 2012]

13. Centers for Disease Control and Prevention, 2011. National Healthcare Safety Network (NHSN) Report, Data Summary for 2010, Device-associated Module. Centers for Disease Control and Prevention, Atlanta, Georgia. http://www.cdc. gov/nhsn/PDFs/dataStat/NHSN-Report_2010-Data-Summary. pdf [Accessed May 21, 2012]

14. Scheckler WE. Surveillance, foundation for the future: A historical overview and evolution of methodologies. American Journal of Infection Control 1997; 25(2): 106-111. http://dx.doi.org/10.1016/S0196-6553(97)90036-5

15. Murphy DM. From expert data collectors to interventionists: changing the focus for infection control professionals. American Journal of Infection Control 2002; 30: 120-132. http://dx.doi.org/10.1067/mic.2002.120526

16. Gaynes R, Richards C, Edwards J, et al. Feeding back surveillance data to prevent hospital-acquired infections. Emerging Infect Dis 2001; 7(2): 295-298. http://dx.doi. org/10.3201/eid0702.010230

17. National Healthcare Safety Network. Data collection forms. Centers for Disease Control and Prevention, Atlanta, Georgia. http://www.cdc.gov/nhsn/ [Accessed May 21, 2012]

18. Pottinger JM, Herwaldt LA, Perl TM. Basics of surveillancean overview. Infect Control Hospital Epidemiology 1997; 18: 513-527. http://dx.doi.org/10.1086/647659
19. Centers for Disease Control and Prevention. Nosocomial infection rates for interhospital comparison: limitations and possible solutions. Infection Control Hospital Epidemiology 1991; 12: 609-621. http://dx.doi.org/10.1086/646250

20. Piriyawat $P$, Šmajsová $M$, Smith MA, et al. Comparison of Active and Passive Surveillance for Cerebrovascular Disease. American Journal of Epidemiology 2002; 156(11): $1062-$ 1069. http://dx.doi.org/10.1093/aje/kwf152

21. Haley RW, White JW, Culver DH, Hughes JM. The financial incentive for hospitals to prevent nosocomial infections under the prospective payment system. JAMA 1987; 257: 1611-1614. http://dx.doi.org/10.1001/jama.1987.03390120073026

22. Haley RW. Managing hospital infection control for cost effectiveness: a strategy for reducing infectious complications. Chicago: American Hospital Association 1986.

23. Collins J. Good to Great: Why Some Companies Make the Leap and Others Don't. New York: Harper Collins Publishers 2001.

24. Friedman C. Infection Prevention and Control Programs. In: Association for Professionals in Infection Control and Epidemiology, Eds. APIC Text of Infection Control and Epidemiology, 3rd edn. Washington, DC: Association for Professionals in Infection Control and Epidemiology 2009; 1-18.

25. Baker OG. Process surveillance: An epidemiologic challenge for all health care organizations, American Journal of Infection Control 1997; 25(2): 96-101. http://dx.doi.org/10.1016/ S0196-6553(97)90034-1

26. Institute of Healthcare Improvement, 2011. Implement the Institute of Healthcare Improvement Central Line Bundle. Institute of Healthcare Improvement. http://www.ihi.org/ knowledge/Pages/Changes/ImplementtheCentralLineBundle. aspx [Accessed August 24, 2012]

27. Institute of Healthcare Improvement, 2012. Implement the Institute of Healthcare Improvement Ventilator Bundle. Institute of Healthcare Improvement. http://www.ihi.org/ knowledge/Pages/Tools/HowtoGuidePreventVAP.aspx [Accessed August 24, 2012]

28. Horan TC, Lee TB. Surveillance: Into the next millennium. American Journal of Infection Control 1997; 25(2): 73-76. http://dx.doi.org/10.1016/S0196-6553(97)90031-6

29. Wright M. Automated surveillance and infection control: toward a better tomorrow. American Journal of Infection Control 2008; 36: S1-S5. http://dx.doi.org/10.1016/j. ajic.2007.09.003

30. Langmuir AD. The surveillance of communicable diseases of national importance. New England Journal of Medicine 1963; 268: 182-191. http://dx.doi.org/10.1056/ NEJM196301242680405 